\title{
A Study Survey on Risk Factors Associated with Breast Cancer in Bangladeshi Population
}

Sharmin Afroz', Shafkat Shamim Rahman ${ }^{2}$ and Md. Mahboob Hossain ${ }^{3 *}$

${ }^{1}$ Department of Pharmacy, University of Asia Pacific, Dhaka, Bangladesh

${ }^{2}$ United Surgical (BD) Ltd., Gazipur, Bangladesh

${ }^{3}$ Department of Mathematics and Natural Sciences, BRAC University, Dhaka, Bangladesh

\begin{abstract}
Background: The occurrence of breast Cancer is a rising concern in Bangladesh. A hospital based case control study was conducted.

Methodology: A nationwide representative sample of 100 out of 115 cancer patients aged 20 or older was interviewed at NICRH to provide information on awareness of the risk factors of breast cancer causes in Bangladeshi population.

Results and discussion: Highest number of patients was from 40-49 (39\%) and 30-39 (27\%) year-age group About $15 \%$ patients had direct family history, $21 \%$ had early periods. About $14 \%$ have got late menopause. If women begin menopause after age 55 , the risk increases. $15 \%$ women have had not had children, and $10 \%$ had their first child after age 30 . Study found women using birth control pills (47\%), have slightly greater risk. $9 \%$ women's breast feeding lasts below 1 year. And about $7 \%$ patient never breast fed their child. About $40 \%$ female patients do not walk as exercise.
\end{abstract}

Conclusion: Results suggested a mixture of different factors with Aging and direct family history poses higher risk for breast cancer.

Keywords: Breast cancer; Ductal carcinoma; Lobular carcinoma; Risk factors

\begin{abstract}
Abbreviations: DCIS: Ductal Carcinoma In-Situ; LCIS: Lobular Carcinoma In-Situ; IBC: Inflammatory Breast Cancer; ILC: Infiltrating Lobular Carcinoma; IDC: Infiltrating Ductal Carcinoma; BRCA1: Breast Cancer 1; BRCA2: Breast Cancer 2; PHT: Post-menopausal Hormone Therapy; HRT: Hormone Replacement Therapy; DSC3: Desmocollin-3; MASPIN: Mammary Serine Protease Inhibitor; DNMT: DNA Methyltransferase; NICRH: National Institute of Cancer Research and Hospital.
\end{abstract}

\section{Introduction}

Breast cancer is a threatening neoplasm that begins in the cells of the breast in women and men. Around the world, breast cancer is the second most common type of cancer after lung cancer $(10.4 \%$ of all cancer incidence, both genders counted) [1] and the fifth most common cause of cancer death. In 2004, breast cancer caused 519,000 deaths worldwide ( $7 \%$ of cancer deaths; almost $1 \%$ of all deaths) [2].

The two most common types of breast cancer are named after their origin-(i) most common Ductal carcinoma begins in the tubes (ducts) that move milk from the breast to the nipple. Around $85 \%$ to $90 \%$ of all breast cancers are ductal. If the cancer is DCIS (ductal carcinoma in situ), it is well contained, not intrusive, and can be effectively treated. And (ii) Lobular carcinoma starts in parts of the breast, called lobules, those produce milk. The lobes are located deeper inside the breast, under the ducts. About $8 \%$ of breast cancers are lobular. If the cancer is LCIS (lobular carcinoma in situ) then the disease is constrained inside the projection and has not spread.

Breast cancer is usually, but not always, principally classified by its histological appearance. Uncommon variations are characterized on the premise of physical exam findings. For example, inflammatory breast cancer (IBC), a type of ductal carcinoma or malignant cancer in the ducts is recognized from different carcinomas by the inflamed appearance of the affected breast [3].

\section{Epidemiology}

The quantity of cases worldwide has essentially expanded since the 1970s, a wonder somewhat faulted for advanced ways of life in the Western world [4]. The occurrence of breast cancer fluctuates significantly around the globe, being lower in less-developed nations and most prominent in the more-developed countries [5]. Women in the United States have the most elevated frequency rates of breast cancer in the world [6]. A few studies have found that black women in the U.S. are more likely to die from breast cancer despite the fact that white women are more likely to be diagnosed with the illness $[7,8]$. Research is progressing to define the impact of both biological and cultural factors $[7,9]$.

\section{Treatment}

Emerging observations suggested that inhibiting the catalytic activity of epigenetic writers might create a new direction for the treatment of human malignant carcinomas. For instance, previous study demonstrated that inhibition of histone methyl transferase G9a leads to the reactivation of tumor suppressors DSC3 and MASPIN in breast cancer [10]. It has been found that the main functions of G9a

${ }^{*}$ Corresponding author: Dr. M. Mahboob Hossain, Department of Mathematics and Natural Sciences, BRAC University, Dhaka-1212, Bangladesh, Tel: +88028824051; E-mail:mmhossain@bracu.ac.bd

Received December 30, 2016; Accepted May 22, 2017; Published May 26, 2017

Citation: Afroz S, Rahman SS, Hossain MM (2017) A Study Survey on Risk Factors Associated with Breast Cancer in Bangladeshi Population. J Cancer Sci Ther 9: 463-467. doi: 10.4172/1948-5956.1000460

Copyright: (C) 2017 Afroz S, et al. This is an open-access article distributed unde the terms of the Creative Commons Attribution License, which permits unrestricted use, distribution, and reproduction in any medium, provided the original author and source are credited. 
are establishing of $\mathrm{H} 3 \mathrm{~K} 9 \mathrm{me} 2$ and protection of loss of imprinted DNA methylation [11,12]. Indeed, in breast cancer cells that treated with G9a inhibitor, a reduction of $\mathrm{H} 3 \mathrm{~K} 9 \mathrm{me} 2$ has been observed and this inhibition is mimicked via using 5-Aza-2'-deoxycytidine, an inhibitor for DNA methyltransferases [10]. Taken together, aberrantly established H3K9me2 and abnormal distribution of DNA methylation marker might play a role in the initiation of breast cancer and inhibition either G9a or DNA methyltransferase (DNMT)s might be a novel and promising direction for the treatment of this disease.

\section{Materials and Methods}

\section{Description of study area}

The study was reviewed and approved by national institute of cancer research and hospital (NICRH). All newly diagnosed cases of cancer patients aged 20-80 were identified by collaborating physicians in NICRH. For each case, patient's registry files obtained and reviewed. The interview was conducted by close and personal meeting. The methodology was:

a. Critical perusal of secondary sources (e.g. books, article, reports, websites etc.)

b. Primary data collection through field interviews, case studies and questionnaires

c. A detailed review of the first draft of the report through consultation with the supervisor.

A detailed three-part questionnaire was developed on the basis of the existing literature, opinion and suggestion received from the supervisor and seniors.

\section{Interviews and questionnaire}

In person structure interviews were conducted were control cases and the next-of-kin of deceased cases. Of the 115 eligible cases identified, 15 refuted, which gave the final count as 100 . Information was obtained about demographic characteristics, occupation and residence histories, living condition, history of selected medical condition and family history of cancer, diet, reproductive history and passive smoking.

At first medical history of patient was asked as the demographic profile may sometimes lead the patient to an embarrassment and they refused to answer. So, data was collected from the registration form of NICRH. In every question, there were some options to assist. The sampling procedure was non-probabilistic and convenience sampling. Percentage and frequency of the attributable fractions were calculated for each risk factor of cancer.

\section{Results and Discussion}

A sum of 100 subjects responded to the interview, response rate was lower in the 20s strata than in the other age groups, but no trend to an increase in response rate with increasing age was observed. Overall no significance differences in area age dispersion was between the specimen population and study respondents. Response rate tended to be lower among subjects who reside in the Barisal division and in urban communities other than five divisions that among other subjects [13-18].

\section{Overview of Risk Factors}

The present survey revealed, targeted at the Bangladeshi cancer patients for female, cancer is causing by contraceptive method, reproductive history, age, tobacco chewing, viral and bacterial contamination and women hygiene had a tendency to be higher than major lifestyle factors such as dietary factors (Table 1).

A founding paper of this subject was the work of Janet Lane-Claypon [19], distributed a near study in 1926 of 500 breast cancer cases and 500 controlled patients of same background and life style for the British ministry of health. With the use of computer, the unit was the first to comply large amounts of cancer data. Cutting edge epidemiological strategies are closely connected to latest concept of disease and public health policy over the past 50 years, great endeavors have been spent on mustering information across medical practice, hospital, provincial state and even national boundaries as an approach to examine the inter dependence of environmental and cultural factors of confirmation.

For British most concerning issue confronting cancer epidemiology today is the changing idea of "Cancer Incidence". For example - a breast cancer tumor with a very slow growth rate may be found with a mammogram 50 years. While the same tumor may have been found as a noteworthy lump at 760 years, depending on the specific growth factor effecting on the particular patients' case as diagnostic tools improved this has a direct impact on the epidemiological data.

The present study revealed that most of the cancer patients used to take imbalanced diet. Data indicates that most cancer s appeared to be related to environmental factors and diet is one of the factors and that diet is one of this factor which appears to play a vital role. Results from epidemiological, clinical, and animal studies have suggested that1) a reduction in total calories decreases risk for a number of tumor type, 2) dietary protein is directly correlated with the risk of cancer, 3) increase dietary fat is correlated with increased risk for breast cancer but we found that Bangladeshi female patients take quite a low fat in their diet. The present study showed that only about $22 \%$ patients take sufficient fat in their diet. Though the female cancer patients do not take much of fat they are the victims of breast cancer (Table 2). About $15 \%$ of female cancer patients were found to have familial history of cancer which corresponds to other reports (Table 2) [20]. Hereditary abnormalities can be classified into two classes: inherited and acquired. Inherited genetic abnormalities are present in the genetic molecules of each of the estimated 50 trillion body cells of an adult human, because the genetic abnormalities were present in the fertilized egg by contrast, acquired genetic abnormalities are acquired by individual cells during one individual's life term, and are only present in the cell which are

\begin{tabular}{|l|l|l|}
\hline $\begin{array}{l}\text { Risk factors that cannot } \\
\text { be changed }\end{array}$ & Significantly higher risk & Previous history of breast cancer \\
\cline { 2 - 3 } & Moderately higher risk & $\begin{array}{l}\text { Age and gender [13,14], Direct family history of breast cancer [13], Genes [15] (e.g. BRCA1 and } \\
\text { BRCA2) }\end{array}$ \\
\cline { 2 - 3 } & $\begin{array}{l}\text { Slightly higher risk } \\
\text { Late menopause, Overweight or obese [16], Excessive radiation, Other cancer in the family, Heritage } \\
\text { [17], Race, Hormone Replacement Therapy (HRT). }\end{array}$ \\
\hline Risk factors from lifestyle & $\begin{array}{l}\text { Use of contraceptives, Postmenopausal hormone therapy (PHT), Combined PHT, ERT, Breast-feeding, } \\
\text { Alcohol [17], Lack of physical exercise. }\end{array}$ \\
\hline Uncertain risk factors & High fat diets [16], Antiperspirants and bras, Abortions, Pollution, Tobacco Smoke [18]. \\
\hline
\end{tabular}

Table 1: Factors of breast cancer causes among the Bangladeshi patients. 
Citation: Afroz S, Rahman SS, Hossain MM (2017) A Study Survey on Risk Factors Associated with Breast Cancer in Bangladeshi Population. J Cancer Sci Ther 9: 463-467. doi: 10.4172/1948-5956.1000460

descendants of those particular cells. Acquired genetic abnormalities can range from very small chromosomal changes to complex adjustment in chromosomal structure. Several lies of proof persuade most cancer scholars that malignancy incepts its development from one genetically abnormal cell. Indeed, in order to become malignant, that one cell certainly must accumulate several predisposing genetic abnormalities in addition to any predisposing genetic abnormalities which are available from heredity. The Scandinavian twin study does not disparage the significance of acquired genetic abnormalities in the causation of behavior of cancer cells. Unfortunate individual inherits genetic abnormalities which can predispose every cell to become malignant, but the full set of genetic abnormalities required for malignancy is inherited seldom, instead of the full set is accumulated in a particular cell over time. And the likelihood of accumulation is the same cell is dictated by the cells environment- by its introduction to agents which can cause alterations in the cells genetic molecules. Because the significance of acquired genetic abnormalities in causing

\begin{tabular}{|l|c|c|}
\hline \multirow{2}{*}{ igh fatty food diet ratio } & Excessively Taken & Not Taken \\
\cline { 2 - 3 } & $22 \%$ & $78 \%$ \\
\hline \multirow{2}{*}{$\begin{array}{l}\text { direct family history (mother, sister or } \\
\text { daughter) ratio }\end{array}$} & Yes & No \\
\cline { 2 - 3 } Passive smoking ratio & $15 \%$ & $85 \%$ \\
\hline \multirow{2}{*}{ Use of plastic container ratio } & $72 \%$ & Nos \\
\hline \multirow{2}{*}{ Physical activity (walking) ratio } & Used & Not Used \\
\cline { 2 - 3 } & $86 \%$ & $14 \%$ \\
\hline \multirow{2}{*}{$\begin{array}{l}\text { Marital status at the time of the disease } \\
\text { diagnosed ratio }\end{array}$} & Yes & No \\
\cline { 2 - 3 } & $60 \%$ & $40 \%$ \\
\cline { 2 - 3 } & Married & Unmarried \\
\hline
\end{tabular}

Table 2: Survey results of factors contributing in development of Breast cancer. the disease is very widely acknowledge, no discontinuity truly exists in hereditary and environmental causes of cancer.

In the present investigation $21.4 \%$ female patients were reported to have weakened immune system as observed by other authors. All cancer is the result of an immune system that did not destroy mutant cells. Obviously, cancer cells are foreign to the body. The immune system of a healthy person destroys 10000 mutated cells every day. When this defense ceases, the cancer cell can multiply and become a clinical case of cancer.

It is observed that the chances of getting cancer increases with age [20] (Figure 1A), female 53.4\% patient similar findings while reported by other authors. The largest risk factor for developing cancer is age. There are a number of known and suspected causes an age dependent susceptibility to cancer. 1) Mutations increase with age, 2) aging tissue and cellular micro environment, 3) tumor suppressor and longevity assurance genes, 4) life time carcinogenic exposure, 5) decreased ability to repair DNA, 6) oncogene activation and amplification, 7) decrease tumor suppressor gene activity, 8) micro environment alteration, including hormonal alterations or exposures, 9) decreases immune surveillance due to immune senescence.

Among female cancer patients $56.5 \%$ had abnormal reproductive function such as age administration, age at first birth (Figure 1B), parity, breast feeding (Figure 1C) and age at menopause were considered involvement of these risk factors were observed by other authors. Every woman's hormone levels change throughout her life for a Varity or reasons and hormone changes can lead to changes in the breasts. Hormone changes that occur during pregnancy may influence a woman's chances of developing breast cancer.

Women, who had their first menstruation at an early age (before 12)
(A) Age Distribution

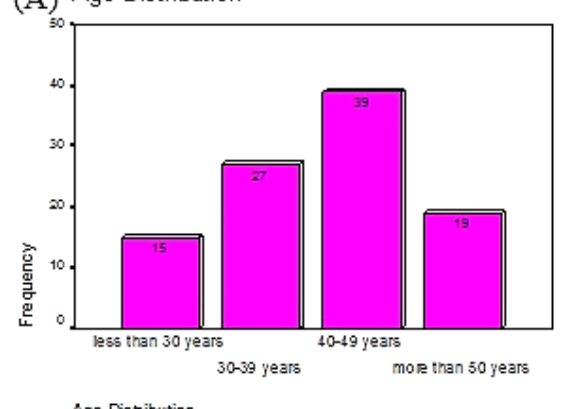

Age Distribution

(C)
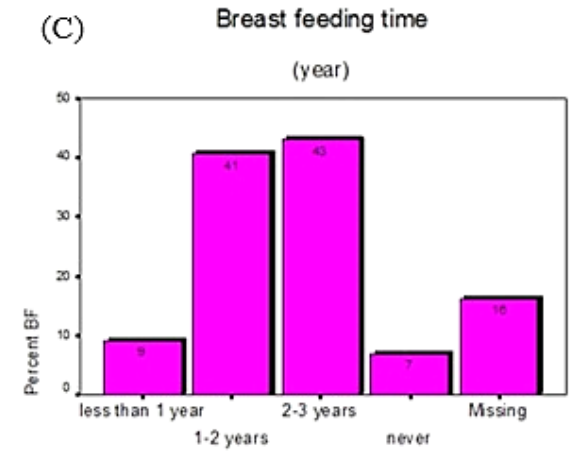

(B)

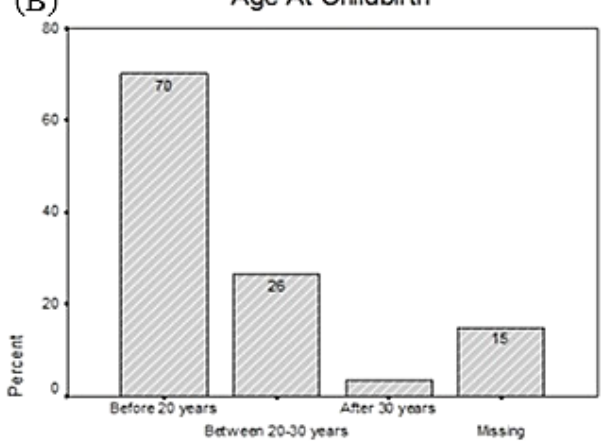

(D)Parity \& Breast cancer

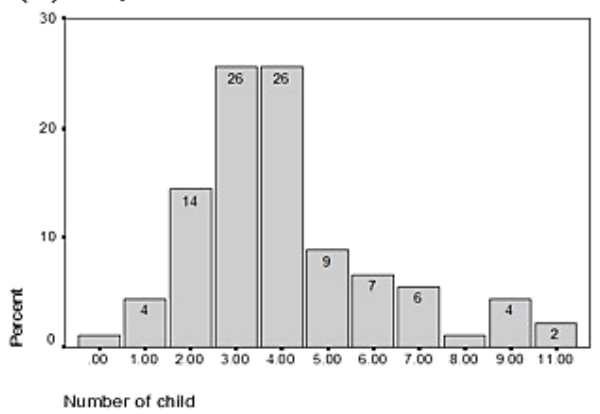

Figure 1: (A) Age distribution (Aging is a major risk factor of breast cancer.), (B) Age at the birth of the first child, (C) Not breast feeding, (D) Not having children or having them later in life. 
Citation: Afroz S, Rahman SS, Hossain MM (2017) A Study Survey on Risk Factors Associated with Breast Cancer in Bangladeshi Population. J Cancer Sci Ther 9: 463-467. doi: 10.4172/1948-5956.1000460

or went through menopause later than normal after 55, are at higher risk of developing breast cancer (Figure $2 \mathrm{~A}$ and $2 \mathrm{~B}$ ), Hormones can prolong the growth rate of cell high levels of hormones specific to the reproductive years of a woman, particularly if they are not hindered by the normal hormone changes of the pregnancy; seem to increase the risk for breast cancer. Some studies propose that even breast feeding can diminish the risk for developing breast cancer if continued until the $18^{\text {th }}$ to $24^{\text {th }}$ month. Pregnancies and breast feeding reduce the number of menstrual cycle during a woman's lifetime (Figure 1D and Table 3).

$47 \%$ female cancer patients were observed to have history if contraception causes different type of cancers (Figure 2C), Smith and his associates also observed many women successfully endured the amenorrhea or irregular bleeding which frequently accompany use of long-acting "progestogen only" methods, there is a substantial minority, particularly in certain ethnic groups, who find this unsuitable. The extensive writing does indicate that albeit combined estrogen-progestogen once-a-month injectables deliver much more regular bleeding patterns than long acting injectable like depotmeroxyprojesterone acetate the patterns are not entirely normal. Detailed studies by the World Health Organization have shown some deviation from normal menstrual patterns by user of the two-once-amonth injectable, Cyclofem and mesigyna. These caused breast cancers ( 60\%) [21]. Contraceptive pills might play in breast cancer risk. Studies have found that women now using oral contraceptive pills have a slightly greater risk of breast cancer than women who have never used them.

(A)

\section{Early menstruation}

(before age 12)

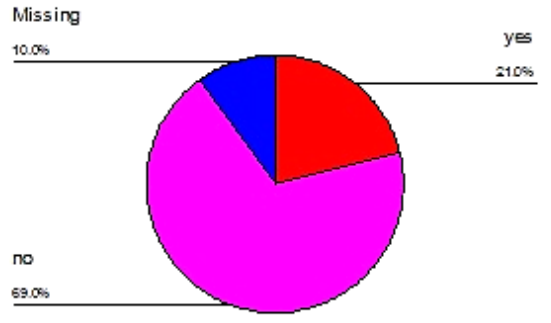

(C)

Contraceptive pils

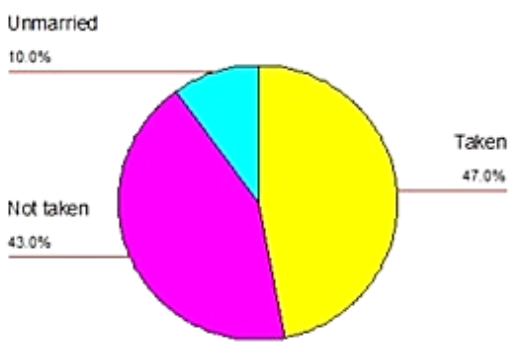

Most studies found no link between active cigarette smoking and breast cancer. The study showed that about $72 \%$ patient do secondhand smoke (Table 2). About $86 \%$ patients use plastic container in their daily house hold activities (Table 2). About $40 \%$ female patients do not walk for 2 hours in a day. Only $60 \%$ patients walk for two hours per day (Table 2). Previous reports also suggested the relationship between lack of physical activity and development of the disease [20]. About $91 \%$ female patients were married at the time of the disease diagnosed (Table 2).

In this study $31.4 \%$ breast cancer patients were found to have the history of induced abortion. The reason is actually quite simple: early in pregnancy, amid the first trimester, hormones animate breast development in preparation for milk production. That development take place in two phases, both of which have to complete or a woman runs a risk for malignancy. In the primary phase, the hormone estrogen makes breast cells multiply repeatedly. This rapid increase in multiplying breast cells continues until other the $32^{\text {nd }}$ week. At that point, in a normal pregnancy, fresh chemical messengers instruct the breast cells to convert from multiplying cells to milk production cells. Once a multiplying cell has been converted to a milk production cell, it does not ever switch back. Its capacity to multiply is turned off forever. Our result corresponds with other result in different countries.

\section{Conclusions}

In final comments, consciousness of the attributable fraction of cancer causes among the Bangladeshi female cancer patient history
(B)

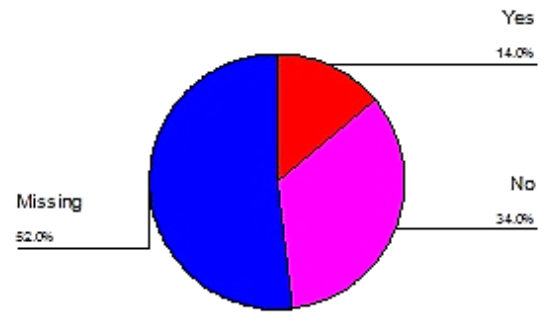

Late menopaused

(after age 55)

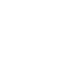


Citation: Afroz S, Rahman SS, Hossain MM (2017) A Study Survey on Risk Factors Associated with Breast Cancer in Bangladeshi Population. J Cancer Sci Ther 9: 463-467. doi: 10.4172/1948-5956.1000460

of contraception, abnormal reproductive history, hereditary factors, passive smoking are more prominent than the other component like occupational exposure and dietary factor. The result of the present overview provides valuable insights and viewpoints toward the formulation of Breast cancer prevention procedures in Bangladesh. In 2015-2016 breast cancer was the leading cancer in female in Bangladesh. This study suggests the risk factor of cancer found is similar to reports from other part of the country and the world [22].

\section{Acknowledgements}

Authors are grateful to Dr. Md. Habibullah Talukdar, Associate Professor and Head of National Institute of Cancer Research and Hospital, for giving the permission to do the survey in the hospital and for constructive instruction and suggestion. Also, thankful to Dr. Md. Jahirul Islam (Research Assistant, NICRH), Shamsad Ahmed (Associate Professor, Department of BBA), A.S.M. Ashraful Islam (Associate Professor, Department of Pharmacy, The University of Asia Pacific) for their graceful co-operation and support.

\section{Conflict of Interest}

None declared.

\section{Funding}

No financial support was received by any of the authors for this study

\section{References}

1. World Health Organization (2003) World Cancer Report, IARC Press.

2. World Health Organization (2006) Cancer fact sheet No. 297.

3. Giordano SH, Hortobagyi GN (2003) Inflammatory breast cancer: Clinical progress and the main problems that must be addressed. Breast Cancer Res 5: 284-288.

4. Laurance J (2006) Breast cancer cases rise $80 \%$ since seventies, the independent, London (Health Editor, Health Correspondent.

5. Stewart BW, Kleihues P (2003) Human cancers by organ site-breast cancer. World Cancer Report. IARC Press, Lyon pp: 188.

6. Ries LAG, Eisner MP, Kosary CL, Hankey BF, Miller BA, et al. (2003) SEER cancer statistics review, 1975-2000. Bethesda, MD: National Cancer Institute.

7. Tammemagi C (2007) Racial/ethnic disparities in breast and gynecologic cancer treatment and outcomes. Curr Opin Obstetr Gynecol 19: 31-61.

8. Hirschman J, Whitman S, Ansell D (2007) The black white disparity in breast cancer mortality: The example of Chicago. Cancer Cause Control 18: 323-333.
9. Demicheli R, Retsky MW, Hrushesky WJ, Baum M (2007) Tumor dormancy and surgery-driven interruption of dormancy in breast cancer: Learning from failures. Nat Clin Pract Oncol. 4: 699-710.

10. Mechanic S, Raynor K, Hill JE, Cowin P (1991) Desmocollins form a distinct subset of the cadherin family of cell adhesion molecules. Proc Natl Acad Sci USA 88: 4476-4480.

11. Tachibana M, Sugimoto K, Nozaki M, Shinkai Y (2002) G9a histone methyltransferase plays a dominant role in euchromatic histone $\mathrm{H} 3$ lysine 9 methylation and is essential for early embryogenesis. Genes Dev 16: 17791791.

12. Zhang T, Termanis A, Özkan B, Bao XX, Culley J, et al. (2016) G9a/GLP complex 1 maintains imprinted 2 DNA methylation in embryonic stem cells. Cell Rep 15: 77-85.

13. Braddock M, Muckenthaler M, White MRH, Thorburn AM, Sommerville J, et al. (1994) Intron-less RNA injected into the nucleus of 4 Xenopus oocytes accesses a regulated translation control pathway. Nucleic Acids Res 22: 52555264.

14. Giordano S, Cohen D, Buzdar A, Perkins G, Hortobagyi G (2004) Breast carcinoma in men: A population-based study. Cancer 101: 51-57.

15. Yager JD, Davidson NE (2006) Estrogen carcinogenesis in breast cancer. N Engl J Med 354: 270-282.

16. Chlebowski RT, Blackburn GL, Thomson CA, Nixon DW, Shapiro A, et al. (2006) Dietary fat reduction and breast cancer outcome: Interim efficacy results from the women's intervention nutrition study. J Natl Cancer Inst 98: 1767-1776.

17. Boffetta P, Hashibe M, La Vecchia C, Zatonski W, Rehm J, et al. (2006) The burden of cancer attributable to alcohol drinking. Int J Cancer 119: 884-887.

18. American Cancer Society (2005) Breast Cancer Facts \& Figures. Accessed on May 23, 2017.

19. Lane-Claypon, Janet E (1926) A Further Report on Cancer of the Breast, with special Reference to its Associated Antecedent Conditions. Reports on Public Health and Medical Subjects No. 32, His Majesty's Stationery Office, 1926, Ministry of Health.

20. American Cancer Society. Breast Cancer Risk and Prevention. Accessed on May 22, 2017.

21. Population Information Program (1995) Center for Communication Programs, Johns Hopkins Bloomberg School of Hygiene and Public Health. Population Reports: New Era for Injectables.

22. Mina LA, Storniolo AM, Kipfer HD, Hunter C, Ludwig KK (2016) Breast Cancer Prevention and Treatment. Springer International Publishing. 